\title{
Should Breast Cancer Surgery Be Done in an Outpatient Setting?
}

\author{
Health Economics From the Perspective of Service Providers
}

Die Operation des Mammakarzinoms - eine ambulante Leistung?

Gesundheitsökonomische Betrachtung aus der Perspektive des Leistungserbringers

Authors

Margaret Formago ${ }^{1 *}$, Michael G. Schrauder ${ }^{1 *}$, Claudia Rauh ${ }^{1}$, Carolin C. Hack ${ }^{1}$, Sebastian M. Jud ${ }^{1}$, Thomas Hildebrandt ${ }^{1}$, Rüdiger Schulz-Wendtland ${ }^{2}$, S. Frentz ${ }^{3}$, S. Graubert ${ }^{3}$, Matthias W. Beckmann ${ }^{1}$, Michael P. Lux ${ }^{1}$

Affiliations

1 Friedrich-Alexander University Erlangen-Nürnberg (FAU), Department of Obstetrics and Gynecology, Erlangen University Hospital, Comprehensive Cancer Center Erlangen-EMN, Erlangen, Germany

2 Friedrich-Alexander University Erlangen-Nürnberg (FAU), Department of Radiology, Erlangen University Hospital, Comprehensive Cancer Center Erlangen-EMN, Erlangen, Germany

3 Friedrich-Alexander University Erlangen-Nürnberg (FAU), Commercial Directorate, Comprehensive Cancer Center Erlangen-EMN, Erlangen, Germany

\section{Key words}

breast cancer, surgery, outpatient setting, DRG (Diagnosis

Related Groups), EBM (Uniform Assessment Scale)

\section{Schlüsselwörter}

Mammakarzinom, Operation, ambulanter Sektor, DRG (Diagnosis Related Groups), EBM (Einheitlicher Bewertungsmaßstab)

received 9.5.2017

revised 19.6.2017

accepted 20.6.2017

\section{Bibliography}

DOI https://doi.org/10.1055/s-0043-114427

Geburtsh Frauenheilk 2017; 77: 879-886 @ Georg Thieme

Verlag KG Stuttgart · New York | ISSN 0016-5751

\section{Correspondence}

Prof. Dr. Michael P. Lux, MBA

Frauenklinik, Universitäts-Brustzentrum Franken, Universitätsklinikum Erlangen, CCC Erlangen-EMN, Friedrich-Alexander-Universität Erlangen-Nürnberg Universitätsstraße 21-23, 91054 Erlangen, Germany michael.lux@uk-erlangen.de

Deutsche Version unter:

https://doi.org/10.1055/s-0043-114427

\section{ABSTRACT}

Introduction The care of patients with breast cancer is extremely complex and requires interdisciplinary care in certified facilities. These specialized facilities provide numerous services without being correspondingly remunerated. The question whether breast cancer surgery should be performed in an outpatient setting to reduce costs is increasingly being debated. This study compares inpatient surgical treatment with a model of the same surgery performed on an outpatient basis to examine the potential financial impact.

Material and Methods A theoretical model was developed and the DRG fees for surgical interventions to treat primary breast cancer were calculated. A theoretical 1-day DRG was then calculated to permit comparisons with outpatient procedures. The costs of outpatient surgery were calculated based on the remuneration rates of the AOP (Outpatient Surgery) Contract and the EBM (Uniform Assessment Scale) and compared to the costs of the 1-day DRG.

Results The DRG fee for both breast-conserving surgery and mastectomy is higher than the fee paid in the context of the EBM system, although the same procedures were carried out in both systems. If a hospital were to carry out breast-conserving surgery as an outpatient procedure, the fee would be $€$ 1313.81; depending on the type of surgery, the hospital would therefore only receive between $39.20 \%$ and $52.82 \%$ of the DRG fee. This was the case even for a 1-day treatment. Compared to the real DRG fees the difference would be even more striking.

Conclusion Carrying out breast cancer surgery as an outpatient procedure would result in a significant shortfall of revenues. Additional services from certified centers, such as the interdisciplinary planning of treatment, psycho-oncological and social-medical care with the involvement of relatives, detailed documentation, etc., which are currently provided without surcharge or adequate remuneration, could no longer be maintained. The quality of processes and excellent results which have been achieved and ultimately the care given by certified facilities would be significantly at risk.

* first shared authorship 


\section{ZUSAMMENFASSUNG}

Einleitung Die Versorgung der Mammakarzinompatientin ist äußerst komplex und erfordert die interdisziplinäre Versorgung in zertifizierten Strukturen, in denen zahlreiche Leistungen ohne entsprechende Vergütung angeboten werden. Dem gegenüber nimmt jedoch die Diskussion um die ambulante operative Mammakarzinomtherapie zur Kostenreduktion zu. Die vorliegende Analyse vergleicht die stationäre operative Therapie mit einem Modell der ambulanten OP-Durchführung, um die potenziellen Auswirkungen näher zu beleuchten.

Material und Methoden Es wurde ein theoretisches Modell entwickelt, in dem zunächst die Entgelte der DRGs der Operationen einer primären Mammakarzinompatientin berechnet wurden. Anschließend wurde eine theoretische 1-Tages-DRG kalkuliert, um eine Vergleichbarkeit zum ambulanten Sektor herzustellen. Folgend wurde die ambulante Operation entsprechend dem AOP-(Ambulantes-Operieren-)Vertrag bzw. dem EBM kalkuliert und der 1-Tages-DRG gegenübergestellt.
Ergebnisse Sowohl bei der brusterhaltenden Operation als auch Mastektomie ist die DRG-Vergütung für eine identische Leistung höher als innerhalb des EBM-Systems. Würde ein Krankenhaus eine brusterhaltende Therapie als ambulanten Eingriff durchführen, so beliefe sich das Entgelt auf 1313,81€ und läge somit je nach OP nur zwischen 39,20\% und 52,82\% der DRG-Entgelte. Und dies trotz der Annahme einer 1-TagesBehandlung. Im Vergleich zu realen DRG-Entgelten wären die Unterschiede deutlich ausgeprägter.

Schlussfolgerung Zusammenfassend würde die ambulante Durchführung der Mammakarzinomoperation zu einer deutlichen Unterdeckung führen. Zusatzleistungen der zertifizierten Zentren, die aktuell ohne Zuschläge und adäquate Vergütung erbracht werden, wie die interdisziplinäre Therapieplanung, die psychoonkologische und sozialmedizinische Betreuung mit Einbindung der Angehörigen, die ausführliche Dokumentation, etc., könnten folgend nicht mehr aufrechterhalten werden. Die erreichte Prozess- und Ergebnisqualität und letztendlich die Versorgung in zertifizierten Strukturen selbst wären deutlich gefährdet.

\section{Introduction}

In Europe 2.45 million people develop cancer every year [1]. Breast cancer is the most common cancer for women in Europe. The overall cost of oncologic disease in the EU amounts to 126 billion Euros annually, of which $€ 28.4$ billion are for inpatient care. Breast cancer is not only a serious diagnostic and therapeutic challenge for the various service providers but, because of its high incidence, it has significant implications for health economics. The diagnosis, treatment, and aftercare of patients with breast cancer require an extremely complex, time-consuming and personnel-intensive range of services at a level not matched by almost any other disease. In Germany, 69550 women develop breast cancer every year. At least 5500 more women develop ductal carcinoma in situ (DCIS) [2]. On average $€ 13$ is spent on breast cancer per person and year in the European Union. Countries such as Lithuania and Bulgaria spend $€ 2$ per person and year on breast cancer. By comparison, Germany spends $€ 29$ per person and year [1].

Since the introduction of the diagnosis-related fee-per-case system (G-DRG, German Diagnosis-Related Groups) in Germany, in addition to medical aspects more and more emphasis is placed on economic considerations. Reducing costs while maintaining or even improving the quality of care is the most urgent objective. Surgical care has been the topic of much heated debate. The Medical Services of the Health Insurance Companies (MDK) are increasingly reviewing cases with the aim of reducing costs. The consequences are a reduction in the length of inpatient stays and deductions to fees when patients are in hospital for less than the minimum stipulated length of stay. In addition, the question whether surgery for breast cancer could be done in an outpatient setting is being increasingly debated. Interventions such as lumpectomy and sentinel lymph node biopsy are already partly listed in the catalog of outpatient surgeries. This in turn places a strain on the providers of services who try to ensure that their costs are covered. Certified centers are under particular pressure as many of the services they provide are not included in the standard scale of fees and are provided as additional services which are not remunerated. Such non-remunerated services include psycho-oncologic care, interdisciplinary tumor boards, further training and advanced training, as well as higher costs for the significantly more detailed documentation they need to provide compared to non-certified centers [3-4]. The current data shows that certified centers deliver better process quality and better results for patients [5-7]. The discussion whether breast cancer surgery should be done in an outpatient setting is increasing the cost pressures on certified centers and endangering the quality of care. According to the annual 2016 report on certified centers, 54405 breast cancers were treated in the 228 certified breast centers in 2015 [8]. A total of 47495 patients with breast cancer underwent surgery. 13801 patients with primary breast cancer had a mastectomy and 33695 patients had breast-conserving surgery.

Because of the high number of cases who undergo surgery and the economic pressure, this health economic analysis aimed to investigate inpatient procedures of patients with primary breast cancer. The fees for procedures were determined and compared with the fees which would be paid if the same procedure were performed in hospital in an outpatient setting in accordance with the terms of $\S 115 b$ SGB V (Volume V of the German Social Insurance Code) [9]. The question this study aimed to answer was whether, from the point of view of service providers, it would be possible to provide the full range of services for breast cancer surgery patients in an outpatient setting while covering the costs incurred. In addition, the study discusses what the expected positive and negative consequences would be for patients if treatment shifted from in-hospital care to an outpatient setting. 


\section{Material and Methods}

\section{Site of evaluation and patient population}

Diagnostic and therapeutic steps, surgical scenarios and average length of hospital stay were determined based on the patient population of the University Breast Center of Franconia (UBF) of the gynecological department of Erlangen University Hospital and the Comprehensive Cancer Center Erlangen-EMN. The UBF has been a certified center since 2004 and meets the certification criteria of the German Cancer Society (DKG) and the German Society for Senology (DGS). A total of 451 patients with primary breast cancer were treated in 2015 . The data of patients with primary breast cancer treated at the UBF in 2015 who underwent breast cancer surgery for the first time, had no relevant secondary diagnosis, and achieved R0 status after surgery were evaluated. The respective diagnoses were coded in accordance with the German version of the ICD-10 (ICD-10-GM) and the respective OPS codes based on the International Classification of Procedures in Medicine (ICPM) of the WHO.

\section{DRG assignment and monetary calculation of inpatient services}

The webgrouper of the DRG Research Group of the University of Münster was used to assign the chosen scenarios to the appropriate DRGs based on their main diagnosis code (ICD-10-GM) and the Operation and Procedure Code (OPS) in accordance with 2015 German coding guidelines [10-11]. The average age of the patient population was used for average patient age. Reason for admission was "referral by physician" and type of discharge was "finished regular treatment". The standard case was defined as "inpatient hospital treatment" in a "main ward". The federal base rate for 2015 which amounted to $€ 3311.98$ was taken as the basis when calculating the DRG fees.

Additional "day-case DRGs" were generated to construe a fee for the 1-day treatment of every envisaged surgical scenario in analogy to the outpatient surgical scenarios.

\section{Development of outpatient models and monetary calculation of outpatient services}

An outpatient surgical procedure was defined as a gynecological surgical procedure carried out using instruments, with the patient under a general anesthetic but without subsequently staying overnight in hospital (hospitalization). The AOP Contract concluded between the umbrella organizations of health insurance providers in Germany, the German Hospital Federation (DKG) and the National Association of Statutory Health Insurance Physicians (KBV) sets out the rules for outpatient surgeries and socalled "non-ward-based in-hospital procedures" [9]. Costs incurred by patients who undergo surgery as outpatients (AOP patients) are settled directly with the patient's health insurance company. Costs incurred by patients who are insured by statutory health insurance companies (GKVs) are reimbursed in accordance with rates of the currently applicable Uniform Assessment Scale (EBM). In the model developed for this study, inpatient services received by the patient cohort were recalculated as outpatient services (with the respective OPS code) in accordance with the
2015 EBM and the reference value for the year 2015 of 10.2718 cents [12].

To compare outpatient services as far as possible with the range of inpatient services provided, the model also took account of the preoperative, intraoperative and postoperative services which were directly linked to the inpatient surgical procedures. Calculations referred to billable services in accordance with the terms of $\S 115 b$ SGB $\vee$ [9]. Individual services were grouped together as flat-rate fees and charges. The costs of materials were entered in the calculation in the form of a flat-rate surcharge of $7.0 \%$ added to the physician's fee (this covered medicines, dressings and aids, materials, single-use infusion sets, biopsy needles, etc.). The contracts do not cover outpatient services provided to privately insured patients, services provided in cooperation with registered physicians in private practice, the presentation of the case to a preoperative and postoperative tumor board, or psycho-oncologic and psycho-social counselling.

\section{Results}

\section{Cohort}

A total of 186 treated patients met the inclusion criteria. Each case was discussed by an interdisciplinary tumor board both prior to treatment and postoperatively. Because of the limited number of cases, the figures for galactography and MRI with contrast agent were not representative and were therefore classified as not relevant for the evaluation. In total, the study differentiated between 13 possible surgical scenarios ( $\bullet$ Table 1 ). The primary therapy for 147 (79\%) patients was breast-conserving therapy (BCT); 58 of them only had additional sentinel lymph node biopsy (SLNB), 74 had regional level I lymphadenectomy and 15 underwent additional level I and II axillary lymph node dissection (ALND). Repeat resection was required in two cases and mastectomy was required in one case to achieve R0 status. Modified radical mastectomy (MRM) was necessary in 39 (21\%) patients, of whom 8 only had SLNB, 20 had additional regional level I lymphadenectomy, and 11 additionally underwent complete level I and II axillary lymph node dissection. The mean patient age was 61.3 years. The mean hospital stay was 4.85 days.

\section{Remuneration for inpatient treatment - DRG fees}

The diagnosis and procedures performed in the patient cohort were categorized into the appropriate DRGs and the fees were calculated ( $\triangleright$ Table 2 ). The 13 investigated surgical scenarios were grouped into one of two DRGs: J07B and J23Z. In accordance with $\S 8$ of the Hospital Remuneration Act, services provided prior to admission to the ward (including basic diagnostics and laboratory diagnostics) could not be billed separately but were remunerated with the DRG fee. In the comparative calculation, costs of materials and instruments were included in the flat-rate fee per case. This also applied to standard contingency costs.

\section{Remuneration of theoretical surgical outpatient procedures based on the EBM}

Based on $\S 4$ of the AOP Contract, the cost of preoperative diagnostics for the patients in our cohort who underwent BCT was cal- 
- Table 1 Surgical scenarios used to treat patients.

\begin{tabular}{|c|c|c|}
\hline Surgical scenario & OPS combinations & Description \\
\hline Scenario 1 & $5-870 . a 1+5-401.12$ & $\mathrm{BCT}(<1$ quadrant) $+\mathrm{SLNB}$ (with color marking) \\
\hline Scenario 1a & $5-870 . a 1+5-401.12+5-406.11$ & $\mathrm{BCT}$ (<1 quadrant) + SLNB (with color marking) + ALND (level I) \\
\hline Scenario $1 b$ & $5-870 . a 1+5-401.12+5-406.12$ & BCT (< 1 quadrant) + SLNB (with color marking) + ALND (levels I and II) \\
\hline Scenario 2 & $5-870 . a 1+5-401.13$ & $\mathrm{BCT}$ (<1 quadrant) + SLNB (with radionuclide and color marking) \\
\hline Scenario $2 a$ & $5-870 . a 1+5-401.13+5-406.11$ & BCT (< 1 quadrant) + SLNB (with radionuclide and color marking) + ALND (level I) \\
\hline Scenario $2 b$ & $5-870 . a 1+5-401.13+5-406.12$ & $\mathrm{BCT}$ (< 1 quadrant) + SLNB (with radionuclide and color marking) + ALND (levels I and II) \\
\hline Scenario 3 & $5-870 . a 2+5-401.12$ & $\mathrm{BCT}(>1$ quadrant) + SLNB (with color marking) \\
\hline Scenario 3a & $5-870 . a 2+5-401.12+5-406.11$ & $\mathrm{BCT}$ (> 1 quadrant) + SLNB (with color marking) + ALND (level I) \\
\hline Scenario 3b & $5-870 . a 2+5-401.12+5-406.12$ & $\mathrm{BCT}$ (> 1 quadrant) + SLNB (with color marking) + ALND (levels I and II) \\
\hline Scenario 4 & $5-870 . a 2+5-401.13$ & $\mathrm{BCT}$ (> 1 quadrant) + SLNB (with radionuclide and color marking) \\
\hline Scenario 4a & $5-870 . a 2+5-401.13+5-406.11$ & BCT (> 1 quadrant) + SLNB (with radionuclide and color marking) + ALND (level I) \\
\hline Scenario 4b & $5-870 . a 2+5-401.13+5-406.12$ & $\mathrm{BCT}$ (> 1 quadrant) + SLNB (with radionuclide and color marking) + ALND (levels I and II) \\
\hline Scenario 5 & $5-872.1+5-401.12$ & MRM + SLNB (with color marking) \\
\hline Scenario $5 a$ & $5-872.1+5-401.12+5-406.11$ & MRM + SLNB (with color marking) + ALND (level I) \\
\hline Scenario $5 b$ & $5-872.1+5-401.12+5-406.12$ & MRM + SLNB (with color marking) + ALND (levels I and II) \\
\hline Scenario 6 & $5-872.1+5-401.13$ & MRM + SLNB (with radionuclide and color marking) \\
\hline Scenario 6a & $5-872.1+5-401.13+5-406.11$ & MRM + SLNB (with radionuclide and color marking) + ALND (level I) \\
\hline Scenario $6 b$ & $5-872.1+5-401.13+5-406.12$ & MRM + SLNB (with radionuclide and color marking) + ALND (levels I and II) \\
\hline
\end{tabular}

- Table 2 DRG fees for inpatient diagnostics and treatment: classic (= relative DRG fee) and hypothesized DRG fee per day (effective DRG fee/“daycase DRG") compared to a theoretical outpatient setting remunerated according to the EBM system.

\begin{tabular}{|c|c|c|c|c|c|c|c|}
\hline $\begin{array}{l}\text { Surgical } \\
\text { scenario }\end{array}$ & OPS combinations & DRG & $\begin{array}{l}\text { Relative } \\
\text { DRG fee }\end{array}$ & $\begin{array}{l}\text { Effective DRG fee/ } \\
\text { "day-case DRG" }\end{array}$ & EBM fee & $\begin{array}{l}\text { Difference } \\
\text { of inpatient to } \\
\text { outpatient }\end{array}$ & $\begin{array}{l}\text { \% day-case } \\
\text { DRG }\end{array}$ \\
\hline Scenario 1 & 5-870.a1 + 5-401.12 & J07B & $€ 4580.47$ & $€ 3351.72$ & $€ 1313.81$ & $€ 2037.91$ & $39.20 \%$ \\
\hline Scenario 1a & $5-870 . a 1+5-401.12+5-406.11$ & $\mathrm{~J} 23 \mathrm{Z}$ & $€ 5140.19$ & $€ 2487.30$ & $€ 1313.81$ & $€ 1173.49$ & $52.82 \%$ \\
\hline Scenario 1b & $5-870 . a 1+5-401.12+5-406.12$ & $\mathrm{~J} 23 \mathrm{Z}$ & $€ 5140.19$ & $€ 2487.30$ & $€ 1313.81$ & $€ 1173.49$ & $52.82 \%$ \\
\hline Scenario 2 & $5-870 . a 1+5-401.13$ & J07B & $€ 4580.47$ & $€ 3351.72$ & $€ 1313.81$ & $€ 2037.91$ & $39.20 \%$ \\
\hline Scenario 2a & $5-870 . a 1+5-401.13+5-406.11$ & $J 23 Z$ & $€ 5140.19$ & $€ 2487.30$ & $€ 1313.81$ & $€ 1173.49$ & $52.82 \%$ \\
\hline Scenario 2b & $5-870 . a 1+5-401.13+5-406.12$ & $J 23 Z$ & $€ 5140.19$ & $€ 2487.30$ & $€ 1313.81$ & $€ 1173.49$ & $52.82 \%$ \\
\hline Scenario 3 & $5-870 . a 2+5-401.12$ & J07B & $€ 4580.47$ & $€ 3351.72$ & $€ 1313.81$ & $€ 2037.91$ & $39.20 \%$ \\
\hline Scenario 3a & $5-870 . a 2+5-401.12+5-406.11$ & $\mathrm{~J} 23 \mathrm{Z}$ & $€ 5140.19$ & $€ 2487.30$ & $€ 1313.81$ & $€ 1173.49$ & $52.82 \%$ \\
\hline Scenario 3b & $5-870 \cdot a 2+5-401.12+5-406.12$ & $J 23 Z$ & $€ 5140.19$ & $€ 2487.30$ & $€ 1313.81$ & $€ 1173.49$ & $52.82 \%$ \\
\hline Scenario 4 & $5-870 . a 2+5-401.13$ & J07B & $€ 4580.47$ & $€ 3351.72$ & $€ 1313.81$ & $€ 2037.91$ & $39.20 \%$ \\
\hline Scenario 4a & $5-870 . a 2+5-401.13+5-406.11$ & $J 23 Z$ & $€ 5140.19$ & $€ 2487.30$ & $€ 1313.81$ & $€ 1173.49$ & $52.82 \%$ \\
\hline Scenario 4b & $5-870 \cdot a 2+5-401.13+5-406.12$ & $J 23 Z$ & $€ 5140.19$ & $€ 2487.30$ & $€ 1313.81$ & $€ 1173.49$ & $52.82 \%$ \\
\hline Scenario 5 & $5-872.1+5-401.12$ & $\mathrm{~J} 23 \mathrm{Z}$ & $€ 5140.19$ & $€ 2487.30$ & $€ 1205.31$ & $€ 1281.99$ & $48.46 \%$ \\
\hline Scenario 5a & $5-872.1+5-401.12+5-406.11$ & $\mathrm{~J} 23 \mathrm{Z}$ & $€ 5140.19$ & $€ 2487.30$ & $€ 1205.31$ & $€ 1281.99$ & $48.46 \%$ \\
\hline Scenario 5b & $5-872.1+5-401.12+5-406.12$ & $\mathrm{~J} 23 \mathrm{Z}$ & $€ 5140.19$ & $€ 2487.30$ & $€ 1205.31$ & $€ 1281.99$ & $48.46 \%$ \\
\hline Scenario 6 & $5-872.1+5-401.13$ & $\mathrm{~J} 23 \mathrm{Z}$ & $€ 5140.19$ & $€ 2487.30$ & $€ 1205.31$ & $€ 1281.99$ & $48.46 \%$ \\
\hline Scenario 6a & $5-872.1+5-401.13+5-406.11$ & $\mathrm{~J} 23 \mathrm{Z}$ & $€ 5140.19$ & $€ 2487.30$ & $€ 1205.31$ & $€ 1281.99$ & $48.46 \%$ \\
\hline Scenario $6 b$ & $5-872.1+5-401.13+5-406.12$ & $\mathrm{~J} 232$ & $€ 5140.19$ & $€ 2487.30$ & $€ 1205.31$ & $€ 1281.99$ & $48.46 \%$ \\
\hline
\end{tabular}


culated as $€ 688.80$, and the cost of preoperative diagnostics for the patients in our cohort who had MRM was calculated as $€ 459.02$. This included diagnostic imaging, punch biopsy, histology and staging (diagnosing the extent of disease). The difference in costs between the two procedures is due to the required wire marking and radiography of specimens from patients who undergo BCT. The cost of preoperative laboratory diagnostics was calculated as $€ 21.15$. It should be noted that currently hospitals are not reimbursed for these costs.

According to $\S 5$ of the AOP Contract, only intraoperative measures which have a direct temporal and medical connection with the procedure are billable. This includes additional procedures such as frozen section analysis of the sentinel lymph node for which the remuneration is $€ 33.39$.

When costing postoperative care, the EBM differentiates between postoperative monitoring and postoperative treatment. In our patient cohort, postoperative monitoring was done by the anesthesiologist, and postoperative treatment was provided by the surgeon. Postoperative monitoring consisted of monitoring the patient's respiratory function, circulation, and vigilance (obligatory care) as well as ECG monitoring and infusion therapy (facultative care). In addition to examining and discussing the resected specimen(s), the latter includes facultative services such as wound care and the removal of drainages and sutures. According to $\S 7$ para. 2 of the AOP Contract, $27.5 \%$ of the points must be deducted from the points calculated for the surgeon. The legislators have justified this deduction by stating that postoperative contacts between patient and surgeon on the day of the operation and postoperative contact on the day after surgery is part of the standard surgical service.

Two examples of billing for surgical procedures are depicted below: one for BCT, which was carried out in 38 patients from our studied cohort ( $\vee$ Table 3 ), and one for MRM ( $\vee$ Table 4 ). MRM was carried out in 17 cases.

Although the surgical scenarios considered here consisted of two (BCT or MRM incl. SLNB) or three (BCT or MRM incl. SLNB and ALND) procedures with different fee schedule positions, no surcharges were payable for other procedures carried out simultaneously, as simultaneous procedures are only billable if their diagnosis and surgical approach differs from the main procedure. If several surgical procedures are carried out under a single diagnosis, then only the procedure with the highest fee can be billed, in this case either BCT or MRM. The fee for the surgical procedure (in this case EBM no. 31113 and EBM no. 31114) covers all medical services provided by the surgeon, examinations on the day of the procedure, final medical examinations after the procedure, one postoperative contact between the physician and the patient, the documentation of the surgical procedure and all consultations including the final report to the physician responsible for further treatment. The EBM does not take account of differences in the consumption of resources depending on the type, extent and severity of the procedure. The flat-rate surcharge of $7 \%$ ( $\S 9$ of the AOP Contract) of the total fee covers all disposable materials, dressings, medicine and aids provided by the hospital.

\section{Comparison of DRG fees and EBM fees}

- Table 2 clearly shows the differences in the traditional remuneration using the DRG system, the theoretical 1-day DRG and, for comparison, remuneration based on the EBM. What is striking is the difference in the remuneration of comparable services when they are performed in an outpatient and in an inpatient setting. This even applies to an assumed 1-day DRG. The DRG remuneration is significantly higher for both BCT and MRM compared to the remuneration for the same surgical procedures provided by the EBM system. If hospitals were to carry out breast cancer surgery, which were previously carried out as inpatient procedures, as outpatient procedures, then the remuneration per procedure would be between 39.20 and $52.82 \%$ (average: $48.28 \%$ ) of the DRG remuneration per procedure (depending on the type and number of procedures), even under the assumption of that the patient will only stay in hospital for 1 day. For example, based on the average base rate of $€ 3311.98$, the fee for a BCT carried out as a 1-day inpatient treatment (OPS: 5-870.a1 or 5-870.a2) performed together with SLNB with color marking (OPS: 5-401.12) or radionuclide and color marking (OPS: 5-401.13) and including preoperative diagnostics would amount to $€ 3351.72$. If the procedure were carried out in an outpatient setting the hospital would receive fee of $€ 540.47$ for the surgical procedure together with $€ 688.80$ for the preoperative diagnostics, $€ 21.15$ for the laboratory diagnostics and $€ 33.39$ for intraoperative services, only amounting in total to $€ 1313.81$. If an MRM were carried out as in an outpatient setting, the hospital would receive a total remuneration of $€ 1205.31$ (amounting to approximately $48.46 \%$ of the DRG remuneration).

\section{Discussion}

In Germany oncological care is largely provided by certified centers which are supported by service providers, the funding agencies and German healthcare policy in the context of the National Cancer Plan. As regards senology, there are enough DKG- and DGS-certified breast cancer centers to provide nationwide coverage [13]. Several publication have already shown that the care of patients with breast cancer provided by certified breast cancer centers is currently not adequately remunerated, and that surcharges are urgently required to cover the costs of the care provided by certified facilities [14-17]. The fact that certain additionally incurred costs are not reimbursable is particularly problematic. Such additional costs include the expenses incurred for (re)certification and the cost of complying with obligatory quality criteria such as training and further training, the costs of research based on molecular studies and clinical trials, and the requirement of multiple documentation [18]. Detailed analyses have been done to show the cost of detailed documentation [3-4]. Depending on the hospital or center costs range from $€ 352.82$ to $€ 1084.08$ for documenting the overall course of treatment from the initial diagnosis to the conclusion of follow-up in patients with breast cancer. Non-certified centers must fulfil fewer requirements, leading to lower overall costs. Other costs incurred by certified centers include the cost of coordinating the centers, support for patients and their families, and the provision of infrastructures for interdisciplinary partners. 
- Table 3 Billing for breast-conserving therapy performed in an outpatient setting (OPS 5-870.a2 incl. 5-401.13 and 5-406.11).

\begin{tabular}{|c|c|c|c|}
\hline ВСТ 5-870.a2 + 5-401.13+5-406.11 & EBM no. & EBM points & Remuneration \\
\hline Basic gynecology flat rate for insured patients aged 60 and above & 08212 & 147 & $€ 15.10$ \\
\hline Basic anesthesiology flat rate for insured patients aged 60 and above & 05212 & 111 & $€ 11.40$ \\
\hline Pre-anesthesia examination for a surgical procedure carried out in an outpatient setting & 05310 & 179 & $€ 18.39$ \\
\hline $\begin{array}{l}\text { 5-870.a2: partial (breast-conserving) breast excision surgery and destruction of breast tissue: } \\
\text { partial resection: coverage of the defect with mobilization and adaptation of more than } 25 \% \text { of } \\
\text { breast tissue (more than } 1 \text { quadrant) }\end{array}$ & 31113 & 2343 & $€ 240.67$ \\
\hline $\begin{array}{l}\text { Anesthesia and/or general anesthesia, administered while carrying out a procedure in accordance } \\
\text { with fee schedule position } 31113\end{array}$ & 31823 & 1542 & $€ 158.39$ \\
\hline $\begin{array}{l}\text { 5-401.13: Excision of individual lymph nodes and lymphatic vessels: axillary lymph node dissection: } \\
\text { with radionuclide and color marking, combined (sentinel lymphadenectomy); category C2 procedure }\end{array}$ & 31122 & 1542 & $€ 158.39$ \\
\hline $\begin{array}{l}\text { 5-406-11: regional lymphadenectomy (dissection of several lymph nodes from a single region) } \\
\text { during a different procedure: axillary lymph node dissection: level 1; category B2 procedure }\end{array}$ & 31112 & 1602 & $€ 164.55$ \\
\hline $\begin{array}{l}\text { Postoperative monitoring following the surgical procedure in accordance with fee schedule position } \\
31113\end{array}$ & 31504 & 743 & $€ 76.32$ \\
\hline $\begin{array}{l}\text { Postoperative treatment by surgeon minus } 27.5 \% \text { points (obligatory care: examination of the specimen } \\
\text { (s), discussion of specimen(s); billing: only one contact in the period between the } 1 \text { st and the } 14 \text { th day } \\
\text { after the procedure is billable) }\end{array}$ & 31609 & 173 & $€ 12.88$ \\
\hline Remuneration & & & $€ 533.15$ \\
\hline Flat-rate surcharge of $7 \%$ for materials & & & $€ 37.32$ \\
\hline Subtotal & & & $€ 570.47$ \\
\hline Preoperative diagnostics & & & $€ 688.80$ \\
\hline Laboratory diagnostics & & & $€ 21.15$ \\
\hline Intraoperative services & & & $€ 33.39$ \\
\hline Total reimbursement for breast-conserving therapy in an outpatient setting & & & $€ 1313.81$ \\
\hline
\end{tabular}

- Table 4 Billing for mastectomy carried out in an outpatient setting (OPS 5-872.1 incl. 5-401.12 and 5-406.11).

\begin{tabular}{|c|c|c|c|}
\hline MRM 5-872.1 + 5-401.12 + 5-406.11 & EBM no. & EBM points & Remuneration \\
\hline Basic gynecology flat rate for insured patients aged 60 and above & 08212 & 147 & $€ 15.10$ \\
\hline Basic anesthesiology flat rate for insured patients aged 60 and above & 05212 & 111 & $€ 11.40$ \\
\hline Pre-anesthesia examination for a surgical procedure carried out in an outpatient setting & 05310 & 179 & $€ 18.39$ \\
\hline 5-872.1: modified radical mastectomy: with resection of the pectoral fascia; category B4 procedure & 31114 & 3117 & $€ 320.17$ \\
\hline $\begin{array}{l}\text { Anesthesia and/or general anesthesia, administered while carrying out a procedure as defined for fee } \\
\text { schedule position } 31114\end{array}$ & 31824 & 1828 & $€ 187.77$ \\
\hline $\begin{array}{l}\text { 5-401.12: Excision of individual lymph nodes and lymphatic vessels: axillary lymph node dissection: with } \\
\text { color marking, combined (sentinel lymphadenectomy); category C2 procedure }\end{array}$ & 31122 & 1542 & $€ 158.39$ \\
\hline $\begin{array}{l}\text { 5-406-11: regional lymphadenectomy ((dissection of several lymph nodes from a single region) during a } \\
\text { different procedure: axillary lymph node dissection: level 1; category B2 procedure }\end{array}$ & 31112 & 1602 & $€ 164.55$ \\
\hline Postoperative monitoring following the surgical procedure as defined for fee schedule position 31114 & 31504 & 743 & $€ 76.32$ \\
\hline Postoperative treatment by the surgeon minus $27.5 \%$ & 31611 & 233 & $€ 17.35$ \\
\hline Remuneration & & & $€ 646.50$ \\
\hline Flat-rate surcharge of $7 \%$ for materials & & & $€ 45.25$ \\
\hline Subtotal & & & $€ 691.75$ \\
\hline Preoperative diagnostics & & & $€ 459.02$ \\
\hline Laboratory diagnostics & & & $€ 21.15$ \\
\hline Intraoperative services & & & $€ 33.39$ \\
\hline Total reimbursement for mastectomy performed in an outpatient setting & & & $€ 1205.31$ \\
\hline
\end{tabular}


The establishment of a center followed by its certification is associated with significantly higher additional costs, but the data shows that centers have a positive impact on the quality of results. From the perspective of the health services, certified centers are therefore cost-effective: they improve the quality of processes and results without the funding agencies having to bear significantly higher costs. Although $\S 5$ para. 2 of the Law on Hospital Fees (KHEntgG) does provide a legal basis for funding the additional costs incurred by certified facilities, surcharges are seldom allowed $[13,16,19]$. Nevertheless, the certified centers still provide a range of services, usually without surcharge, to ensure that patients receive adequate care. Certified centers provide these unremunerated services because there is no wish to risk the high quality of processes and results.

The unremunerated costs incurred by the centers contravene the goals of healthcare policies, which aim to continually improve the quality of treatment and outcomes. Rather than trying to combat the trend towards not remunerating services, inpatient services are increasingly being concentrated into fewer days. The MDK is increasingly monitoring the amount of time spent in hospital: the number of inpatients days are being reduced and inpatient services are being replaced by outpatient procedures. Shorter stays in hospital result in lower fees, pushing up cost pressures and increasing the risk of underfunding.

The flat-rate fee per case should reflect the average stay in hospital of patients receiving the appropriate treatment based on data collected by the InEK (Institute for the Remuneration System in Hospitals) from sample hospitals [20]. To prevent patients in the G-DRG system from being discharged too early, significant deductions are made if a hospital discharges patients quickly or if patients remain in hospital for fewer days than the minimum stipulated length of stay. But the trend of audits by the MDK has increasingly been not to approve some of the days that patients spend in hospital, so that these patients then spend fewer than the minimum stipulated days in hospital. From the perspective of the funding agencies, aspects such as psycho-oncologic care, radioactive marking prior to SLNB, talks with the patient and her family, social-medical counselling and other care services do not justify the patient staying in hospital. The requirements for certified breast centers state that patients should not stay in hospital for fewer than 4 days [21]. This requirement is based on the need for comprehensive holistic care around the actual surgical procedure, care which includes medical-social and psycho-oncologic care provided in hospital. Oncology patients treated in an outpatient setting have only limited access to psycho-oncologic support and the waiting times for support are usually long.

Under the motto "as much done in an outpatient setting as possible, as much done in hospital as necessary", more than ever before funding agencies and the MDK are demanding that services be provided in an outpatient setting to slow down the rise in healthcare expenditure. If women with breast cancer have surgical procedures in an outpatient setting, this will exacerbate the current funding situation and intensify the cost pressures even more.

To examine the potential impact of performing surgical procedures to treat patients with breast cancer in an outpatient setting, this study developed a theoretical model to compare surgical pro- cedures carried out in hospital with those performed in an outpatient setting. The comparison highlighted significant differences in remuneration ranging from 39.20 to $52.82 \%$. The differences were even more pronounced when the comparison was between outpatient remuneration and real DRGs, not the theoretical 1-day DRG. To take the example of mastectomy with SLNB and the additional resection of unmarked, level 1 lymph nodes, the DRG remuneration for patient who stayed in hospital for an average number of days would amount to $€ 5140.19$. The remuneration according to the EBM system would be $€ 1313.81$; the difference in this case would amount to $€ 3826.38$. In this context it is important to consider the effect of the revenue-reducing discounts levied against outpatient surgical procedures which are the result of the non-inclusion of various procedures performed during breast-conserving surgery or mastectomy as well as the deduction of $27.5 \%$ for postoperative treatment by the surgeon. Hospitals which carry out procedures on an outpatient basis would have to absorb a loss of between $€ 164.97$ (including SLNB and with a deduction of $27.5 \%$ ) and $€ 329.53$ (including SLNB, ALND and a deduction of $27.5 \%$ ). In addition, the cost of presenting individual cases to an interdisciplinary tumor board including preparations for the board meeting is not remunerated. Although this has been included in the EBM since October 10, 2015, it is only described as a service provided as part of outpatient medical care (ASV) as defined in $\S 116 \mathrm{~b}$ of the SGB $\vee$ and is therefore not relevant for the evaluation in this study [22].

Even if the assumption that the current inpatient DRG remuneration covers the costs were true, it must be stated that a comparable cost coverage could not be achieved for either BCT or MRM performed on an outpatient basis. If there are no changes to the legal and financial framework conditions, hospitals will not be able to provide surgery for primary breast cancer in an outpatient setting in such a way that the costs are covered. In addition to the problem of adequate remuneration described here, this raises questions about the financing of the additional duties required of certified centers as outlined above. These duties are not remunerated in an outpatient setting. Taking MRM as an example, if the requisite surcharge of $€ 643.65$ were to be added for certified breast centers, a surcharge which patients consider to be justified [23], then the difference in funding would amount to $€ 4470.03$ for the same procedure and services. Performing breast cancer surgery in an outpatient setting would lead to a significant shortfall in remuneration. Moreover, the additional services provided by certified centers which are currently being provided without surcharge or adequate remuneration, such as coordination of the patient, interdisciplinary planning of therapy, psycho-oncologic and social-medical care with involvement of family members, detailed documentation, and ultimately the care provided by certified facilities, could no longer be sustained. The quality of processes and results would be significantly at risk.

This study has certain limitations. It is based on a purely theoretical model. It should be noted that some of the analyzed surgical procedures are not currently listed in the catalog of "Procedures carried out in an outpatient setting and other non-wardbased in-hospital procedures in accordance with §115b SGB V" [9]. Nevertheless, funding agencies are currently of the opinion that certain procedures can be included in the AOP catalog and 
that the services could be provided in an outpatient setting. Moreover, the actual points allotted regionally could differ from national guidelines to take account of regional differences in costs and care facilities. Breast reconstructive surgery was not included in the analysis. This was because of the complexity of procedures and because performing breast reconstruction as an outpatient procedure was not considered realistic. Finally, the actual costs of service providers could be lower for procedures performed on an outpatient basis as the nursing costs and cost of meals, etc. would be lower. The 1-day DRG was created to counteract this limitation. The majority of costs are incurred at diagnosis and surgery, which are identical in both scenarios.

\section{Conclusion}

The focus of the surgical treatment of patients with primary breast cancer must be on providing multimodal treatment in compliance with medical guidelines with the active involvement of well-informed patients and physician-patient contacts based on trust; the focus should not be on measures which are driven by the pressure to save costs. Hospitals and certified centers are not commercially driven facilities; they are demand-driven facilities which discharge a social obligation to provide public healthcare services. In addition to the numerous practical and moral arguments against performing breast cancer surgery in an outpatient setting, this study shows that such a set-up would also place a significant economic burden on hospitals because costs would not be covered.

Conflict of Interest

The authors declare that they have no conflict of interest.

\section{References}

[1] Luengo-Fernandez R, Leal J, Gray A et al. Economic burden of cancer across the European Union: a population-based cost analysis. Lancet Oncol 2013; 14: 1165-1174

[2] Robert Koch-Institut; Gesellschaft der epidemiologischen Krebsregister in Deutschland e.V., Hrsg. Krebs in Deutschland 2011/2012. 10. Ausgabe. Berlin: Gesundheitsberichterstattung des Bundes; 2015: 74-77

[3] Lux MP, Sell CS, Fasching PA et al. Time and resources needed to document patients with breast cancer from primary diagnosis to follow-up results of a single-center study. Geburtsh Frauenheilk 2014; 74: 743751

[4] Beckmann MW, Sell CS, Aydogdu M et al. Dokumentationsaufwand und damit verbundene Ressourcen bei Patientinnen mit einem Mammakarzinom - von der Primärdiagnose bis zur Abschluss der Nachsorge - Ergebnisse der multizentrischen Erhebung. Gesundheitswesen 2016; 78: 438-445

[5] Beckmann MW, Brucker C, Hanf V et al. Quality assured health care in certified breast centers and improvement of prognosis of breast cancer patients. Onkologie 2011; 34: 362-367

[6] Heil J, Gondos A, Rauch G et al. Outcome analysis of patients with primary breast cancer initially treated at a certified academic breast unit. Breast 2012; 21: 303-308

[7] Jackisch C, Funk A, König K et al. Disease management project breast cancer in Hesse - 5-year survival data. Geburtsh Frauenheilk 2014; 74: 276-283
[8] Deutsche Gesellschaft für Senologie e.V.; Deutsche Krebsgesellschaft e.V. Jahresbericht der zertifizierten Brustkrebszentren. Kennzahlenauswertung 2016. Auditjahr 2015/Kennzahlenjahr 2014. Online: http:// www.onkozert.de/aktuelles_160224.htm; last access: 01.03.2017

[9] Deutsche Krankenhausgesellschaft. Vertrag nach §115b Abs. 1 SGB V Ambulantes Operieren und sonstige stationsersetzende Eingriffe im Krankenhaus - (AOP-Vertrag) zwischen dem GKV-Spitzenverband, Berlin, und der Deutschen Krankenhausgesellschaft e.V., Berlin, sowie der Kassenärztlichen Bundesvereinigung, Berlin. 2014. Online: http://www. bvf.de/pdf/richtlinien/AOP_Vertrag.pdf; last access: 16.07.2016

[10] Institut für das Entgeltsystem im Krankenhaus GmbH, Hrsg. Deutsche Kordierrichtlinien 2015: Allgemeine und spezielle Kodierrichtlinien für die Verschlüsselung von Krankheiten und Prozeduren. Praxisausgabe FPV \& DKR 2015. Lich: pictura Werbung GmbH; 2014

[11] DRG-Research-Group Universitätsklinikum Münster. Webgrouper. 2015. Online: http://drg.uni-muenster.de; last access: 21.10.2016

[12] Hermanns PM, Filler G, Hrsg. EBM 2015 - Kommentierter Einheitlicher Bewertungsmaßstab: Aktuelle Leistungen mit Punktangaben und Eurobeträgen auf der Grundlage des bundeseinheitlichen Orientierungswertes von 10,2718 Cent. 5. Aufl. Berlin, Heidelberg: Springer; 2014

[13] Lux M, Hildebrandt T, Beyer-Finkler E et al. Relevance of health economics in breast cancer treatment - the view of certified breast centres and their patients. Breast Care 2013; 8: 15-21

[14] Köckemann M, Lillteicher F. Entgeltverhandlungen 2007 - folgt das Geld der Qualität? Die bislang ausgebliebene Finanzierung zusätzlicher Strukturqualität von Brustzentren in Nordrhein-Westfalen. Das Krankenhaus 2007; 5: 439-445

[15] Wagner S, Ganslandt T, Keiling CM et al. Ist ein Brustzentrum finanzierbar? - Ein Kalkulationsmodell für das Universitäts-Brustzentrum Franken (UBF). Geburtsh Frauenheilk 2007; 9: 966-973

[16] Beckmann MW, Bader W, Bechtold I et al. Finanzierung und finanzielle Probleme von Leistungen und Strukturen im Fachgebiet Gynäkologie und Geburtshilfe im Jahr 2011 - allgemeine Aspekte und geburtshilfliche Versorgung. II. Artikel der Finanzierungskommission der DGGG e.V. - Teil I. Geburtsh Frauenheilk 2011; 71: 497-510

[17] Beckmann MW, Bader W, Bechtold I et al. Finanzierung und finanzielle Probleme von Leistungen und Strukturen im Fachgebiet Gynäkologie und Geburtshilfe im Jahr 2011 - DRG-System und stationäre Versorgung inklusive Urogynäkologie und benigner wie auch maligner gynäkologischer Operationen. II. Artikel der Finanzierungskommission der DGGG e.V. - Teil II. Geburtsh Frauenheilk 2011; 71: 367-380

[18] Lux MP, Fasching PA, Löhberg CR et al. Health services research and health economy - quality care training in gynaecology, with focus on gynaecological oncology. Geburtsh Frauenheilk 2011; 71: 1046-1055

[19] Beckmann MW, Bani MR, Loehberg CR et al. Are certified breast centers cost-effective? Breast Care 2009; 4: 245-250

[20] Scharl A. Kürzungen gefährden die Versorgung von Brustkrebspatientinnen. Forum 2012; 6: 450

[21] Deutsche Krebsgesellschaft e.V.; Deutsche Gesellschaft für Senologie e.V. Erhebungsbogen für Brustkrebszentren. Inkraftsetzung am 14.07.2016. Online: http://www.onkozert.de/brustkrebszentren.htm; last access: 08.04.2017

[22] Kassenärztliche Bundesvereinigung. Beschluss des ergänzten erweiterten Bewertungsausschusses nach $\S 87$ Abs. 5 a SGB V zur Anpassung des Einheitlichen Bewertungsmaßstabes zur Vergütung der Leistungen der ambulanten spezialfachärztlichen Versorgung gemäß § 116 b Abs. 6 Satz 8 SGB V mit Wirkung zum 01.10.2015. Online: http://www.kbv.de/ media/sp/ASV_2015_10_01_Erg_Erw_BA_02_BeeG_Beschluss_ Aufnahme_Praeambel_Abschnitt_50.2_V2.pdf; last access: 26.09.2016

[23] Thiel FC, Scharl A, Hildebrandt T et al. Financing of certified centers: a willingness-to-pay analysis. Arch Gynecol Obstet 2013; 287: 495-509 